\title{
ELECTRONIC COMMERCE, THE INTERNET AND TRAVEL CYBERMEDIARIES
}

\author{
Paul F. O'Brien \\ Information Systems Group \\ Business Faculty \\ Sunshine Coast University College \\ Locked Bag No. 4, Maroochydore South, Qld, 4558, Australia \\ Email pobrien@scuc.edu.au \\ Doctor of Philosophy Student \\ Department of Computer Science and Electrical Engineering \\ University of Queensland \\ Queensland 4072 Australia \\ and \\ Distributed Systems Technology Centre Pty Ltd \\ Department of Computer Science and Electrical Engineering \\ University of Queensland \\ Queensland 4072 Australia
}

\begin{abstract}
The purchase of a very expensive, complex holiday requires a great deal of information and reliable expert advice. The risks involved in such a purchase are substantial. Industry opinion leaders believe that consumers will continue to take advice from a human sales consultant before purchasing, with the exception of major corporate bookings and simple point to point bookings.

This paper investigates the likely disintermediation effects of electronic commerce on Retail Travel Agents. It provides the basis for the development of a strategic framework for intermediaries that can be used to enhance business performance. The findings of exploratory interviews with travel industry opinion leaders are presented, together with recommended strategic responses for Retail Travel Agents.
\end{abstract}

\section{KEYWORDS}

Tourism, Information Technology, Electronic Commerce, Travel Agent, Internet

\section{INTRODUCTION}

The purchase of a very expensive, complex product or service such as an extended international holiday requires a great deal of information and reliable expert advice. The risks involved in such a purchase are substantial. It is for this reason that opinion leaders in the travel and tourism industry believe that for the foreseeable future, most consumers will continue to take advice from a human sales consultant before purchasing, with the exception of major corporate bookings and simple point to point bookings.

This research investigates the likely disintermediation effects of electronic commerce on the travel industry with a view to developing a strategic framework to guide intermediaries in the travel marketing channels on how to take advantage of any potential opportunities and how to minimise potential threats through the use of information technology.

\section{INFORMATION TECHNOLOGY IN TOURISM AND TRAVEL}

Information technology has become progressively more important to the travel and tourism industry. The most dramatic change came in the 1980s with the introduction of central reservation systems (CRSs). CRSs increased the power of the airlines in the distribution chain and dramatically altered the balance of power in the wholesale travel market (Poon, 1993). Electronic commerce over the Internet is the next major wave of technological change that will hit the industry.

Tourism is an information intensive industry. Fast, efficient exchange of information between the players in the industry is essential for efficient distribution, sales and customer service. Information and communication technologies currently play a vital role and are poised to play an increasingly important role as global, universal access to the Internet, and its progeny, becomes a reality. These emerging new technologies will allow more effective marketing and distribution of services and will release existing staff from back-office tasks so that more time can be spent in "high touch" customer services (Poon, 1993).

Information technology is having, and will continue to have, dramatic effects on the travel industry as it,

- substantially alters the roles of intermediaries in the distribution chain (Poon, 1993) 
- facilitates the production of "new, flexible travel products and services that are cost-competitive with mass, standardised and rigidly packed" products" (Poon, 1993)

- assists in transforming "tourism and travel into a more flexible, individual-oriented, sustainable and diagonally integrated industry" (Poon, 1993)

Whoever controls the information, will control the channel.

\section{CURRENT TRENDS IN THE TRAVEL INDUSTRY}

In the past, distribution was closely tied to settlement. Electronic ticketing and settlement will separate settlement from distribution, enabling new, flexible packaging structures (Eastman, 1996).

There is a worldwide trend towards independent travel (Queensland Tourist \& Travel Corporation, 1997; Poon, 1993). Even the concept of a packaged holiday has changed dramatically over recent years. A typical package is now a fly-drive holiday with hire car and accommodation vouchers, or perhaps a semi-personalised package assembled from a number of mini-packages (Travelworld, Poon 1993), the size of which is getting smaller.

The industry is facing increased competition through globalisation and de-regulation., changing customer demands for more specialised trips, increasing customer expectations, particularly in relation to customisation and increasing knowledge and sophistication of customers. (Bloch \& Segev, 1996).

\section{DISINTERMEDIATION RISKS OF NEW INFORMATION TECHNOLOGY}

Very few empirical studies have been carried out to identify the intermediaries that are most likely to be affected by electronic commerce, or the likely extent of the disintermediation.

There has been considerable discussion in the travel industry press about the inevitable "disintermediation" of travel agents as a result of the widespread availability of the Internet and IT in general. However, "from an academic point of view the "disintermediation" hypothesis is little documented, especially with respect to its underlying theoretical arguments and implications" (Van der Heijden, 1996).

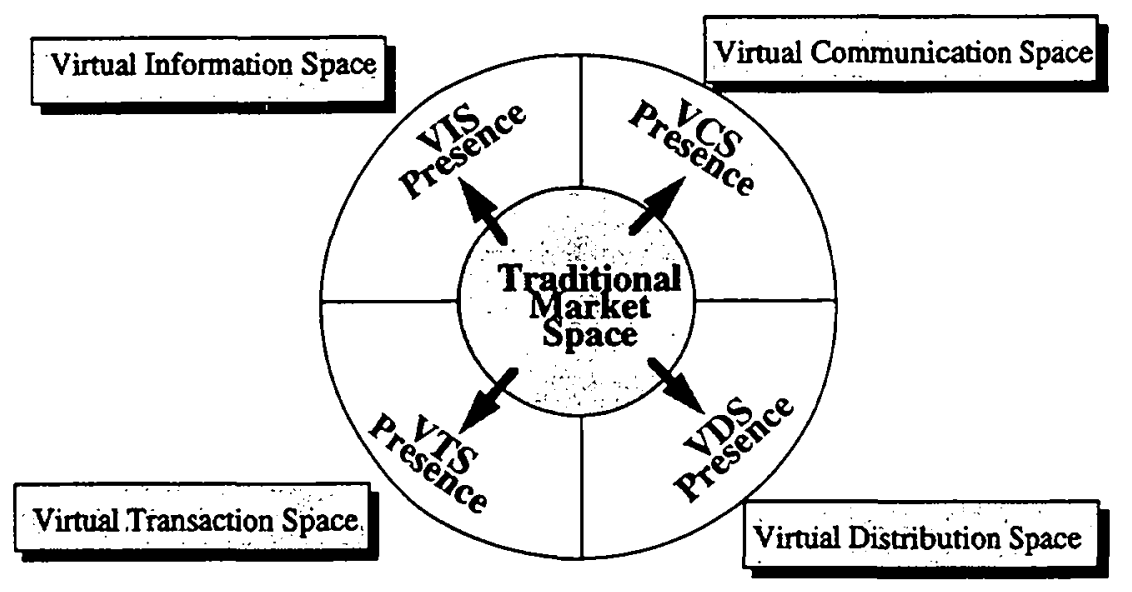

Angehm, 1997

Figure 1: The ICDT Model

Internet commerce has introduced new, virual market spaces in addition to the traditional physical market spaces. Angehrn (1997) introduced a generic framework, the ICDT model (Figure 1) to classify and illustrate significant business opportunities and threats generated by the Internet. The model describes four new, virtual market spaces that are being created by the Internet. They are the information, communication, transaction and distribution spaces. Angehrn treats each space separately because they each require different strategies and technological approaches.

The virtual information space is where company, product and price information is provided to the customer. It is a one-way communication channel. The virtual communication space is where interaction and relationship building with the customer occurs. The virtual distribution space is where products and services are delivered. Since it is a 
virtual space, it is only suitable for delivery of digitised products and services. The virtual transaction space is where orders, invoices, and payments occur.

Figure 2 shows this model applied to the travel industry.

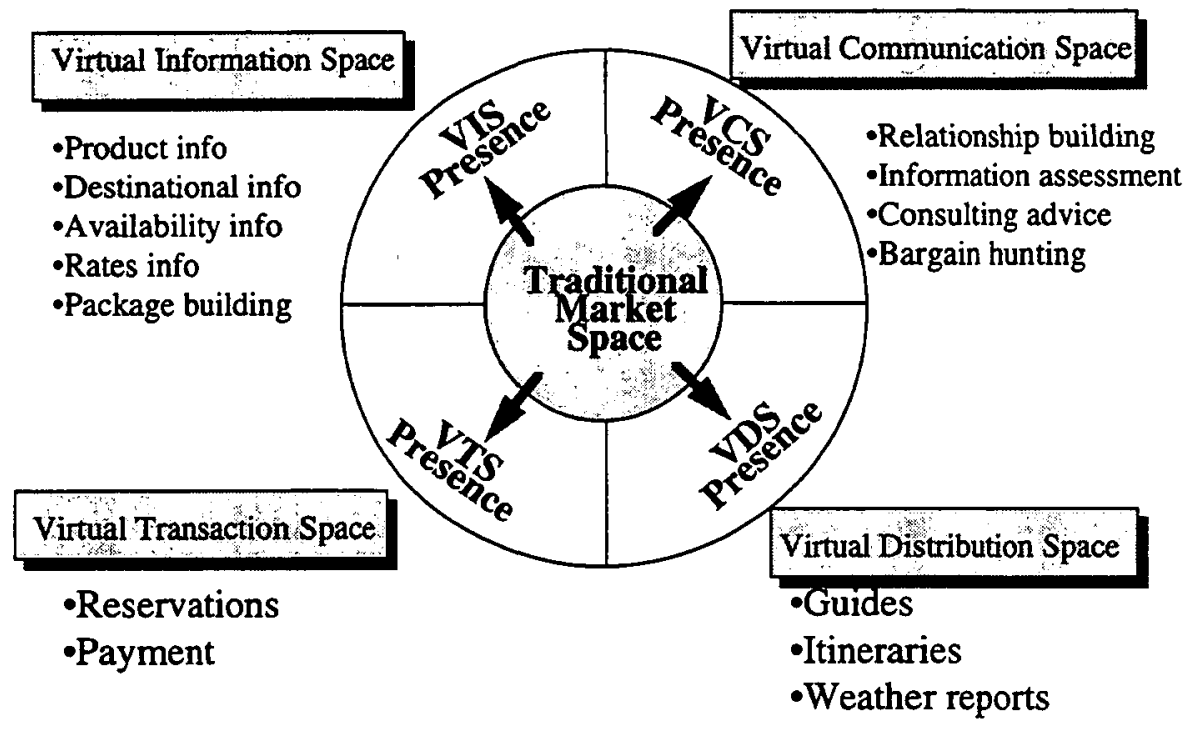

Figure 2: The Travel Industry ICDT Model

The risk of disintermediation is related to the ease with which technology can be used to replace the role of an intermediary in each of these virtual spaces.

Bloch and Segev (1996) proposed that the positive impacts of electronic commerce for existing intermediaries would be :

- raising of entry barriers for new entrants by increasing customer switching costs

- faster introduction of new products

- re-intermediation of new intermediaries acting as information brokers

Bloch and Segev (1996) argue that electronic commerce will have most impact on industries where customer service and information play an important role in the buying process. This category would include industries such as banking, travel and retailing of commodities such as books, $\mathrm{CDs}$, and wine. When their methodology was applied to the travel industry, and travel agents specifically, the greatest impact was shown to be on the travel agent's roles as transaction processors (ticketing and settlement) and suppliers of raw unprocessed, product information. These roles will continue to be replaced by technology as suppliers provide standard product information, electronic ticketing and electronic funds transfer services directly to the consumer. The role of advisor, critically assessing product and destinational information and assisting the consumer to make a suitable choice based on their preferences, was not seen to be under any real threat. This indicates that travel agents need to re-position and focus on the latter role if they are to survive and grow.

Brenner, Kolbe and Hamm (1996) and Lenz (1996) support Bloch and Segev's position. Brenner, Kolbe and Hamm investigated the risk of disintermediation in the Academic book publishing industry and concluded that the risk is related to the ability of information technology to replace the core competencies of the intermediaries. Lenz concluded that the roles that are most easily replaced by technology, transaction processing and information provision, will be the first to be automated, as has already happened with the banks.

The recent moves by airlines to cap or reduce travel agent's commission and continuing expansion of direct sales to consumers, highlights the vulnerability of the transaction space. Similarly, focussing on recommending and selling preferred suppliers standard packaged products, presumably because of higher commissions or lower cost of sale, compromises the travel agents perceived independence and value added in the mind of the customer.

Poon (1993) asserts that "Players closest to consumers (eg. travel agents, hotels) and those in control of the industry's information are expected to gain". Since the travel agent is the closest intermediary to the customer at the point of sale (and usually the point of departure), the risk of disintermediation will be minimal if they are operating in an area that is difficult to replace with IT. The market spaces where the greatest risk of disintermediation exists 
for travel agents are the transaction, information and distribution spaces. The space where least risk exists is the communication (or relationship) space. This may seem paradoxical since information and communications technologies are creating the risks. However, Angehrn (1997) defines the communications space as the space where person to person communication takes place and is therefore minimally affected by communications technology itself. Communications technology simply provides the infrastructure that allows the exchange of information between human participants at either end of the communications channel. It does not enhance the message, it simply delivers it.

\section{RE-INTERMEDIATION OPPORTUNITIES}

While information technology is designed to capture, store and process information, it is not capable (at this stage) of capturing, storing and analysing the "semantics" of that information to the same level of performance as a human expert. The Internet is a huge repository of information but it still requires a human intermediary to assess the reliability, quality and appropriateness of the retrieved information. Over time this situation will improve as more standardisation and controls are put in place, but the anarchic nature of the Internet will make it extremely difficult to enforce.

Poon (1993) argues that if travel agents adopt an appropriate strategic response to the changes that are occurring, there will be enormous prospects for increased income generation. "It is to ensuring the satisfaction of the travel consumers that agencies must give priority in order to ensure their long-term survival and competitiveness. The ability of travel agents to acquire, provide and transmit unbiased information in a courteous, efficient and timely manner will be the key to their competitive success." (Poon, 1993)

More recent literature (Bloch \& Segev, 1996; Karcher, 1996; Milne, 1996; Ng \& Sussman, 1996), electronic ticketing initiatives by the airlines, and the opinions of the participants in this study indicate that ticketing is rapidly reducing in importance and the ability to create personalised packages is now vitally important.

Given that provision of advice is a core competency, then the risk of disintermediation will increase only if provision of advice can be easily replaced by technology. This is highly unlikely in the short term. At the same time, the quality of the advice provided by Retail Travel Agents should be significantly improved by access to reliable, high quality destinational information (Milne,1996), through the Internet, assisting them to reposition to more of a consulting role.

Real opportunities exist for the travel agent of the future to become a network information broker (Lamp \& Keen, 1997) by finding, assessing and quality controlling information obtained from the Internet and other electronic and physical sources and conveying it, together with appropriate advice, to the customer in a clearly understandable form.

\section{THE CHANGING ROLE OF RETAI TRAVEL AGENTS}

Exploratory interviews were carried out with travel industry opinion leaders, retail travel consultants and recent travellers to compare their views on the effects of electronic commerce on Retail Travel Agents with those expressed in the literature.. The main findings were:

- Direct bookings via the Internet are not having a significant impact

- Simple point to point bookings are expected to increasingly be made directly

- Customers are tending to do research on the Internet, then book through a Retail Travel Agent

- Customers are becoming more sophisticated and knowledgeable and are looking for more exotic, specialised holidays

- Niche marketing will become increasingly necessary

- Customers are requiring increasing package personalisation

- The relationship with the customer is everything

- Fee for service is inevitable. It is just a matter of when and how

- Travel agents will increasingly become agents of the people who are travelling rather than agents of the principals, airlines, wholesalers and operators

- A number of travel agent that exist today will not survive - those that don't re-position 


\section{Current Travel Agent Positioning}

Figure 3 shows the current positioning of Retail Travel Agents within Angehrn's virtual market spaces. Their roles are heavily weighted to the transaction, distribution and information spaces, the very spaces where technology is likely to have the greatest disintermediation effects.

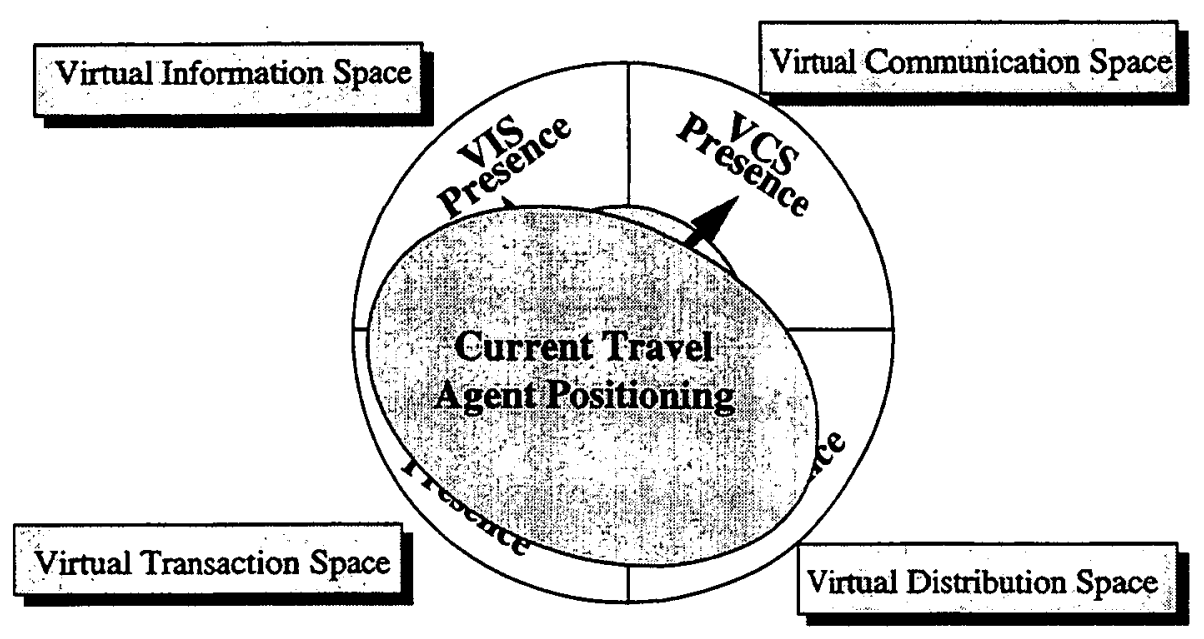

Figure 3. Current Travel Agent Positioning

\section{The Need to Add Value}

An intermediary will only survive in a distribution channel while it continues to add value (Porter, 1985). This research has shown that the traditional roles of travel agents, transaction processing and information delivery, are being rapidly de-valued by electronic commerce. At the same time, the changing attitudes and preferences of customers and the explosion in available travel information on the Internet have increased the value of their consulting (or relationship) and information broking roles. A continual shift towards the later two roles will be essential if they are to continue to add value.

\section{The Importance of Relationships}

The importance of building a relationship with the customer and clearly understanding his/her preferences is not a new concept. It was the theme of the keynote address by Richard Goeglein at the Travel and Tourism Research Association Conference in Memphis in 1986. Goeglein stated that "The conventional wisdom was to offer what was convenient for the operator to provide, or what was better than the competition, rather than to define what the customer wanted and then be sure he/she received it.....we can no longer afford the kind of thinking that puts industry assumptions about the customer ahead of a committed effort to gather facts about the customer " (Goeglein, R., 1986).

More recently David Near, Galileo International's Senior Vice-President Subscriber Marketing urged agents to “ leverage the great strengths which you have and which everyone else wants. Those strengths include your customer base, a deep knowledge of what it takes to satisfy those customers' needs and strong relationships with them." (Near, 1997)

\section{The Importance of Access to Information}

Customers are demanding higher service levels, better quality information and personalised packages. Information on the Internet, is badly organised, distributed and unstructured. It is a time consuming nightmare (Tschanz \& Klein, 1996) for a customer to access and assess the required information and assemble it into a personalised holiday. Travel agents that have access to appropriate technological tools that can streamline this process, and can use them effectively and efficiently, can improve the quality of advice given considerably (Milne,1996), thereby adding value. 
Local tourist operators at most destinations are typically small to medium sized tourism enterprises (SMTEs), are normally organised on a regional or national level by means of public tourist boards (Werthner, 1996) and are not typically accessible through CRSs. Consequently the information required by the "new tourist" is not accessible to most travel agents who typically only have CRS terminals (and no access to the Internet). As a result, the advice given by these travel agents is based on incomplete information at best, or incorrect information at worst.

Research in the United Kingdom has shown that an information system that integrates economic, social, cultural and environmental information at the destination level is required to ensure the long-term prosperity of SMTEs and destinations (Buhalis, 1996). Development of such systems is equally important to travel agents as they require this information to provide quality advice to their customers.

\section{ENHANCING RETAIL TRAVEL AGENT PERFORMANCE}

Internet commerce presents significant opportunities for travel agents to improve their performance by re-positioning themselves to roles that increase the value they add.

\section{Future Travel Agent Positioning}

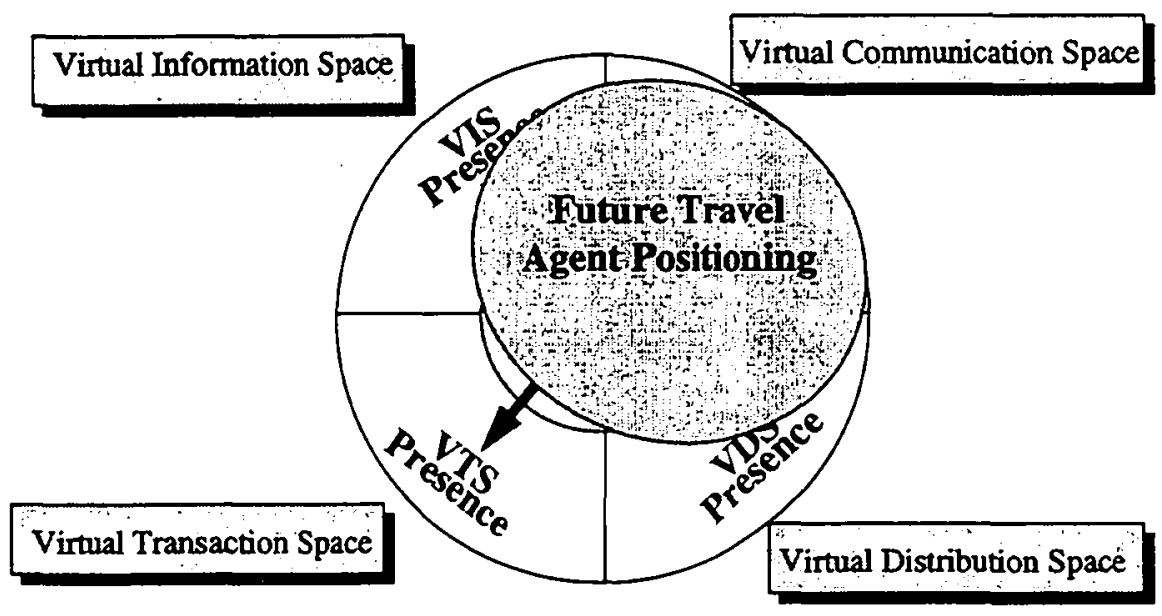

Figure 4. Future Travel Agent Positioning

The literature and the exploratory interviews with industry opinion leaders indicate that travel agents will need to re-position themselves from simple transaction processors, information providers and simple resellers to consultants, information brokers and developers of personalised products if they are to survive. Figure 4 shows the required future positioning of Retail Travel Agents.

\section{Travel Information Broker}

Direct contact between suppliers and consumers via the Internet will result in consumer information overload. To address this problem, new intermediaries will emerge to help the consumer integrate and analyse information (Bloch \& Segev,1996; Lamp \& Keen,1997). In the short to medium term this role can be filled by travel agents using sophisticated software tools and agents.

Retail Travel Agents must become proficient at using these tools, and their own personal experience and knowledge, to access, integrate, analyse, interpret and present information from distributed, heterogeneous sources. This is a difficult task when the consultant has personal knowledge of the activity, product or destination but it is almost impossible when he/she has no personal knowledge or experience. In these situations the software agent must be able to search semantically for relevant products or destinations to meet the new demands of the "new tourist" (Geyer et al, 1996).

This view is supported by David Near, Galileo International's Senior Vice-President Subscriber Marketing who was recently quoted as saying that ".the proliferation of "info-junk" would require a new breed of info-navigators employing advanced information technologies to enhance and deliver their services" (Near, 1997). 
A similar view was expressed by Des Paroz of Southern Cross Galileo who said that "the Internet was "an enormous repository of information" which could be used for background research and passed on to customers, adding value to travel agent's services (Paroz, 1997).

\section{Travel Consultant}

The consulting role of the travel agent must move away from transaction processing to personalised consulting advice focussed on the needs of the customer rather than the needs of the airlines and wholesalers. A particular problem facing any travel consultant is matching the customer's requirements to available destinations and/or products. This is a complex operation that requires a high level of intelligence. The process is complicated by the fact there are no universal standards for the classification and description of destinations and products (Baker et al, 1996). For example, hotel classifications are different in each country and in some cases in each state within a country. In addition, some features that are important to the customer are not rated at all, for example, friendliness of the staff. In many cases an exact match of customer preferences to available products or destinations will not be possible. In this situation, consultants can only do their best to get the closest match possible with the available information. To get an accurate match, the semantics of the customer's preferences must be mapped to the semantics of the features of the product or destination.

Baker et al (1996) recognised that "there is clearly a need for an intelligent system that incorporates local knowledge, regularly updated, and interpretation of the customers' needs, into the mapping process. Intelligent agents, either obeying rules when they exist, or observing and recording in order to learn or infer the correspondence, seemed ideally suited."

The travel agent, assisted by such an intelligent software agent, would create a very powerful travel cybermediary that could dramatically improve the quality of advice provided to the customer, and ultimately, improve customer satisfaction.

While this should allow retail travel agents to survive in the short term, the rapidly increasing technology skills of their customers are likely to reduce the perceived added value of this information broking role. Travel agents will need to "continually redefine themselves" (Sheldon, 1997) and operate in increasingly specialised niche markets if they are to survive. This will require a change in role to relationship building and counselling so that they are able to clearly understand the customer's needs (Ng \& Sussmann, 1996).

\section{Personalised Package Developer}

The changing preference of customers for more individual, personalised holidays requires the travel agent to develop skills in integrating sub-products from different suppliers into a personalised package tailored to the customer's needs and preferences. This is a complex, time-consuming activity that must be highly automated to reduce the cost of sale and make it cost effective. Intelligent itinerary builders that have access to a wide range of packages, minipackages and independent operators' products from a wide range of sources including the Internet and CRSs will be required.

Some work has been done on the development of prototype intelligent agents that assist in the selection of suitable holiday packages (IMTAS/CaBaTa) (Lenz, 1996) however little work has been done on the development of intelligent agents that assist in the selection and assembly of components into personalised holiday packages. This is a rich area for future research.

\section{CONCLUSION AND FURTHER RESEARCH}

"The experience of shopping is probably the only thing that electronic media will never really be able to fully replicate. It should therefore be fully exploited in the real world." (Bloch \& Segev, (1996)

To minimise the risk of disintermediation, and to improve business performance, travel agents should reposition themselves to the virtual spaces where technology will have least effect, and should make maximum use of technology in the other spaces to enhance their core competencies and value added. They will need to reduce their dependence on income from transactions and increase their income from intelligent, knowledge based activities such as counselling, information broking and package personalisation.

Fast, easy access to reliable product, destinational and personal experience information is shown to be critical to the survival of travel agents as consumer preference for personalised packages to more exotic destinations grows. 
The difficulty in finding, accessing and analysing a growing ocean of information indicates the need for an intelligent travel agent assistant. However, the limited abilities of current intelligent agents, and the extremely complex and "personal" nature of an extended holiday to an exotic destination mandate the continuing use of human travel consultants, working with intelligent agents. Together, the travel agent and the intelligent agent will act as a travel network information broker, working on behalf of the customer, and hopefully for a consulting fee.

The development of a suitable digital representation of the customer's desired experience and preferences, and the features of the product or destination, and an intelligent assistant that can interpret this information, search for matching products and destinations within all the sources of information available to it, assess the reliability and quality of the information accessed and make a range of recommendations to the human travel consultant is the subject of further research by the author.

\section{REFERENCES}

Australian Federation of Travel Agents (1994) Travel Industry Technology - Towards Information Highways, Sydney, Australian Federation of Travel Agents.

Angehrn, A. (1997) The Strategic Implications of the Internet, Proceedings of the 1997 European Conference on Information Systems

Baker, M., Lockwood, A. \& Sussman, S. (1996) Application Standards for Tourism Products. Proposals for a program of research, Proceedings of the 3rd International Conference on Information and Communications Technologies in Tourism, Springer-Verlag, Vienna.

Brenner, W., Kolbe, L. \& Hamm, V. (1997) The Net: Extinction or Renaissance for Intermediaries - An Analysis of Core Competencies in the Book Business, Proceedings of the 1997 European Conference on Information Systems.

Bloch, M. \& Segev, A. (1996) The Impact of Electronic Commerce on the Travel Industry, The Fisher Centre for Information Technology \& Management, University of California, California.

Buhalis, D. (1996) Information and telecommunication technologies as a strategic tool for tourism enhancement at destination regions, Proceedings of the 3rd International Conference on Information and Communications Technologies in Tourism, Springer-Verlag, Vienna.

Geyer, G., Kuhn, C. \& Schmid, B. (1996) An Electronic Catalog for Distributed Environments, Proceedings of the 3rd International Conference on Information and Communications Technologies in Tourism, SpringerVerlag, Vienna.

Goeglein, R. (1986) Technology and Tourism : A growing partnership, Proceedings of the 17th Annual Conference of the Travel and Tourism Research Association Conference, Tourism and Travel Research Association, Salt Lake City.

Karcher, K. (1996) Re-engineering the Package Holiday Business, Proceedings of the 3rd International Conference on Information and Communications Technologies in Tourism, Springer-Verlag, Vienna.

Lenz, M. (1996) IMTAS: Intelligent Multimedia Travel Agent System, Proceedings of the 3rd International Conference on Information and Communications Technologies in Tourism, Springer-Verlag, Vienna.

Milne, S. (1996) Tourism Marketing and Computer Reservations Systems in the Pacific, Tourism in the Pacific: Issues and Cases, International Thomson Business Press, London.

Near, D. (1997) Travelweek. (30 July, p 16).

Open Buying on the Internet Consortium (1997) Open Buying on the Internet Standard, Release V1.0, The OBI Consortium, USA.

Paroz, D. (1997) Travelweek. (30 July, p 17)

Poon, A. (1993) Tourism, Technology and Competitive Strategies, CAB International, Wallingford.

Porter, M. (1985) Competitive Advantage, Free Press, New York.

Queensland Tourist \& Travel Corporation (1997) International Marketing Briefs.

Sheldon, P. (1997) Tourism Information Technology, CAB International, New York.

Travel and Tourism Research Association (1986) Technology and Tourism: A Growing Partnership, Proceedings of the 17th Annual Conference of the Travel and Tourism Research Association, Salt Lake City: Bureau of Economic and Business Research.

Tschanz, N. \& Klein, S. (1996) Internet Strategy Development in Tourism - Concept and Case Study, SISnet Research Workshop 'Internet and Business', SISnet, Lisbon. 
Van der Heijden, J. (1996) The changing value of travel agents in tourism networks: towards a network design perspective, Proceedings of the 3rd International Conference on Information and Communications Technologies in Tourism, Springer-Verlag, Vienna.

Werthner, H. (1996) Design Principles of Tourist Information Systems, Proceedings of the 3rd International Conference on Information and Communications Technologies in Tourism, Springer-Verlag, Vienna.

\section{ACKNOWLEDGEMENTS}

The author acknowledges the assistance provided by Dr. Robert Colomb, University of Queensland and Jill Dunn, Sunshine Coast University College in clarifying and focussing the concepts in this paper.

The work reported in this paper has been funded in part by the Cooperative Research Centres Program through the Department of Prime Minister and Cabinet of the Commonwealth Government of Australia 